\title{
Retiring as a Physician during the 2020 Coronavirus Pandemic
}

\author{
Philippa Sprinz ${ }^{1}$ \\ ${ }^{1}$ Hasbro Children's Hospital
}

January 11, 2021

TITLE PAGE

Title: Retiring as a Physician during the 2020 Coronavirus Pandemic

Author: Philippa G. Sprinz, MD, MSc

Hasbro Children's Hospital

Division of Pediatric Hematology/Oncology

593 Eddy St

Providence, RI. 02903

philippa.sprinz@lifespan.org

Corresponding Author: Philippa G. Sprinz, MD, MSc

Hasbro Children's Hospital

Division of Pediatric Hematology/Oncology

593 Eddy St

Providence, RI. 02903

philippa.sprinz@lifespan.org

phone: (401) 444-5171

fax: (401) $444-8845$

Main Text Word Count: 1194 words

No Tables, Figures or other material

Keywords: Retiring, Pandemic, COVID 19,

Congratulations! Well done! Bravo! Our compliments and best wishes! I sat outside, looking up at the night sky trying to make sense of everything. I could not. I had hoped, in the silence of night, that I might be able to find some peace and understanding, something positive to hold on to, some equipoise with where I was at in my life, in the midst of a global pandemic. Unfortunately, the cloud ceiling was too low; there were no stars to be seen, to add perspective to my life. I could not grasp my retirement from clinical practice, at this globally distressing time.

My retirement was planned before Covid-19 was a name in the medical lexicon.

I thought I had planned appropriately. Our son-in-law matched for his clinical fellowship some 2600 miles away. I was 65 years old, and had had a wonderful career as a pediatric hematologist/oncologist, training 
in the UK but moving to and practicing in the US for almost 40 years. My new job was going to be to help with grandchildren, so our children could pursue their own medical careers. As I clearly could not work and commute 2600 miles on a regular basis, I reasoned that I should retire from clinical practice.

Practicing as a physician has been incredibly satisfying. It has been my identity. It is how I presented myself to my family, colleagues and friends. I have given so much of my life to my work. At the same time, unfortunately, I had not taken the time to develop other skills that were anywhere near as rewarding. I acquired some hobbies: diversions from the responsibilities of helping and supporting 'my' patients and colleagues, but not skills to keep my mind or body active when I stopped working. As I contemplated no longer working clinically, I developed an anxiety for 'my' patients. I knew I had excellent colleagues to hand my patients on to, but I could not escape the thought that I would be letting my patients down by not continuing to care for them, myself. I argued that I knew their health care needs 'best'. Only, surely I was doing right by our kids and grandkids by helping them at this time.

I found myself thinking over my years in practice. During that time, I saw the five-year survival rate of children with a cancer diagnosis increase from $58 \%$ to $86 \%{ }^{(1)}$; Hodgkin Lymphoma essentially became straightforwardly curable (5 year survival rate of $99.5 \%$ by 2016$)^{(1)}$. Even brain tumors experienced a twenty percent increase in their overall cure rate, $(57.2 \% \text { to } 76.3 \%)^{(1)}$. For individuals with sickle cell disease (SCD) (my particular area of expertise) the survival gain has been more modest: in the 1970s (ten years before the start of my fellowship) $80 \%$ of individuals with SCD died by age 30 years ${ }^{(2)}$. In the 1990s females with sickle cell anemia had an average life expectancy of 48 years and males 42 years ${ }^{(3)}$. Despite these improvements, the care of individuals with SCD still needs new drugs and better curative approaches. Life expectancy, for patients with SCD, is currently 54 years for both sexes ${ }^{(4)}$. This is still signifiantly less than the non-SCD population of 76 years in the US ${ }^{(4)}$. I do, nevertheless, look to the future in my field with optimism. Immunotherapy is in the forefront of cancer care, and sensitive molecular tests are allowing earlier diagnoses and hopefully, more successful treatments. There are a number of new, albeit expensive, drugs now being marketed for SCD. Stem cell transplantation is accepted as a 'curative' option for the disease, and gene therapy is not too far in the future.

Then February 2020: SARS-CoV-2 arrived in the US. This virus has impacted so many lives in so many ways, in circumstances much, much worse than mine. For me, however, it reformatted my retirement. I could not travel to help our children: borders were closed and international travel all but halted. I would stop work with 'nothing to do'. I suddenly needed to understand 'Retirement from being a full time MD', without a 'plan B'. I recognised that not having to share life-threatening diagnoses with families, would take a weight off my shoulders. Instead, nonetheless, I would cease to be one of a team working painstakingly to help children and their families understand life-impacting illnesses: to hopefully feel better, for at least some periods of time. Despite sadnesses, 'pedi heme-onc' definitely has many rewards. Retirement from it includes the loss of deep family relationships and also daily interactions and stimulating meetings with friends and colleagues.

I then wondered: why does one retire when one has a secure job (and no new occupation to move on to), with rewarding work, and a sense of serving 'the greater good'. This, particularly if one is without 'burn-out' that over the years I have watched some of my colleagues experience? Does one really have to retire? A critical aspect of retirement may be to afford practices the opportunity to replenish the workforce with younger, more adaptable workers. Individuals trained recently on newer, clinical approaches and disease management present new skills and may improve efficiency. Does the fact that junior doctors have lesser salaries than those who have been in practice for many years make a difference? Recognising my predicament, I suggested I could help part-time during the pandemic. The coronavirus was not causing so many childhood illnesses, however, to need more pediatric staff and I am no expert in adult medicine.

Notwithstanding concerns over my retirement, I did have an excitement to think that my leaving would afford a younger physician the opportunity to take a leading role in patients' care and eventually have as rewarding a career in pediatric hematology/oncology as I had. So, I took stock: maybe I could volunteer in the community? I reached out to a number of organisations, all of which were very happy to have my 
help, 'just not now', in the middle of a pandemic. I listened in to as many medical and non-medical on-line lectures as I could. I 'attended' virtual conferences, easily, regionally and nationally, without any travel, and contributed to 'Zoom' teaching at my own institution. I worked for an online publishing company and reviewed manuscripts. I was in touch with 'everyone' and tried to support all the vulnerable people I knew.

Ten months into the pandemic, nevertheless, I am still struggling to come to terms with not being a clinician. Did I devote too much time to my patients - that could not be? Should I have paid more attention to hobbies and have developed a 'Plan B'? Probably 'yes'. Will there be a time, after the pandemic has passed, when again I can contribute to 'the greater good' and do more clinical work? Perhaps it is true: 'once a doctor, always a doctor'. But it is more than that: having spent all of my working days caring for others, with responsibilities of making accurate diagnoses, recommending potentially curative management and providing compassionate care when the cure did not come, I now have to learn a new life: a life of giving back without the rewards of clinical practice.

References:

SEER (Surveillance, Epidemiology and End Results program,) 2017

Platt $\mathrm{O}$ et al Mortality in sickle cell disease. Life expectancy and risk factors for early death: N Eng J Med. 1994, Jun 9; 330(23):1639-44

3) Lanzkron S, Carroll CP, Haywood C Jr. Mortality rates and age at death from sickle cell disease: US, 1979 - 2005. Public Health Rep. 2013; 128: 110-116 4) Lubek et al Estimated Life Expectancy and Income of Patients With Sickle Cell Disease Compared With Those Without Sickle Cell Disease: JAMA Network Open. 2019;2(11):e1915374. doi:10.1001/jamanetworkopen.2019.15374, accessed 12/26/2020 